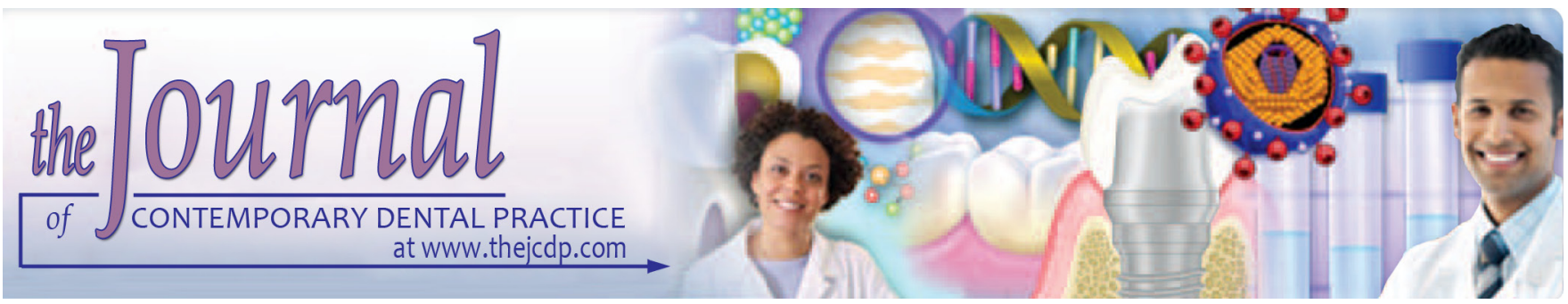

\title{
Anterior Open Bite treated with Myofunctional Therapy and Palatal Crib
}

Moshabab A Asiry

\begin{abstract}
This case report demonstrates the treatment effects of palatal crib combined with the myofunctional therapy in a child with anterior open bite (AOB) due to thumb sucking and habitual anterior and low tongue position. The patient, an 11-year-old boy, had an anterior open bite and flared and spaced upper and lower incisors. Palatal cribs in conjunction with myofunctional therapy were used to discourage sucking habit and to adapt normal tongue position. Successful correction of the AOB with adequate overjet and overbite were achieved with total treatment time of 7 months. The importance of myofunctional therapy in adopting normal tongue position and in maintaining the stability of open bite correction is emphasized.
\end{abstract}

Keywords: Anterior open bite, Myofunctional therapy, Palatal crib.

How to cite this article: Asiry MA. Anterior Open Bite treated with Myofunctional Therapy and Palatal Crib. J Contemp Dent Pract 2015;16(3):243-247.

\section{Source of support: Nil}

\section{Conflict of interest: None}

\section{INTRODUCTION}

Persistent thumb sucking habit protrudes maxillary incisors, develops incompetent lips, interrupts the lip seal required for swallowing, and eventually creates anterior open bite (AOB). Discontinuation of this habit early in mixed dentition stage, with or without habit breaking appliance, usually results in spontaneous correction of AOB. ${ }^{1-3}$ However, thumb sucking habit may be accompanied by abnormal position of the tongue

Division of Orthodontics, Department of Pediatric Dentistry and Orthodontics, College of Dentistry, King Saud University Riyadh, Saudi Arabia

Corresponding Author: Moshabab A Asiry, Assistant Professor, Division of Orthodontics, Department of Pediatric Dentistry and Orthodontics, College of Dentistry, King Saud University, Riyadh, Saudi Arabia, e-mail: masiry@gmail.com during swallowing and at rest, which may accentuate AOB. Failure of tongue posture adaptation might be the primary reason for relapse of AOB. ${ }^{4,5}$ Further, Justus ${ }^{4}$ concluded that anterior tongue rest position is an etiologic factor that frequently overlooked in AOB treatment.

It has been documented in the literature that palatal crib is successful in discouraging thumb sucking habit. ${ }^{4-7}$ In addition, it prevents the tongue from resting on maxillary incisors and help in correcting the AOB. However, the palatal crib may allow the tongue to position itself at low position and prevent the functional re-education of the tongue, and eventually causing relapse of the AOB. ${ }^{5}$ In this situation, myofunctional therapy is necessary to re-educate and adapt the tongue to its normal position.

The following case report will illustrate the treatment effects of palatal crib combined with the myofunctional therapy in a child with $\mathrm{AOB}$ due to thumb sucking and habitual anterior and low tongue position.

\section{CASE REPORT}

\section{Diagnosis and Etiology}

An 11-year-old Egyptian boy presented with a chief complaint of: 'I have spaced and unbeautiful anterior teeth'. He had a convex profile with symmetrical face, recessive chin, acute nasolabial angle (NLA), thick and everted lower lip, acute chin-throat angle, deep mentolabial sulcus, an incompetent lip, no Incisal display at rest, $4 \mathrm{~mm}$ of incisal display at smile, no gingival display at smiling, and nonconsonant smile arc (Fig. 1). The intraoral examination revealed mixed dentition stage with right and left class I molar relationship, an open bite of $5 \mathrm{~mm}$ at the central incisors extending laterally to the canines on both sides, flared and spaced upper and lower incisors, and gingival recession related to mandibular central incisors (Fig. 1). He was a thumb sucker and had anterior and low tongue rest position. 

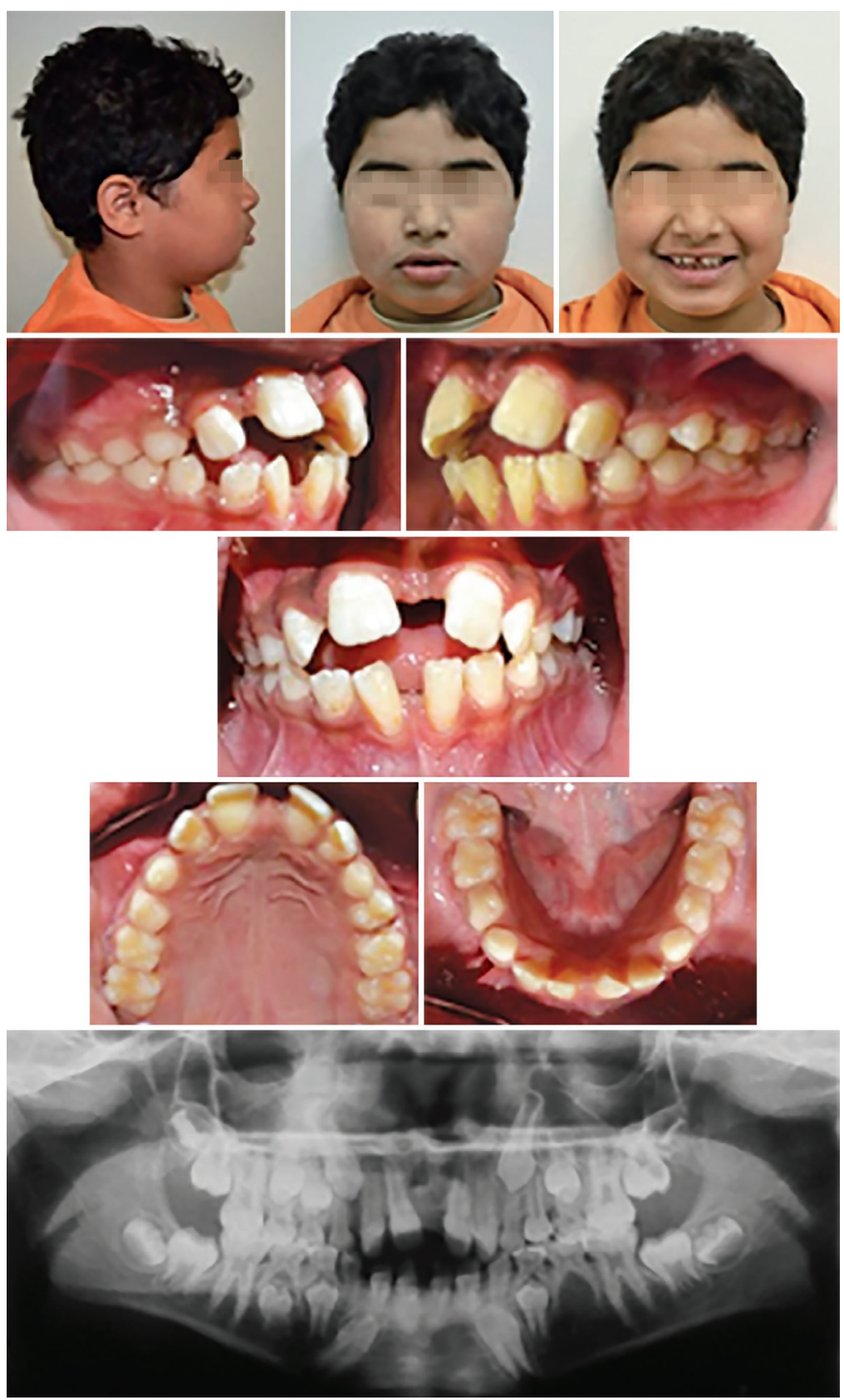

Fig. 1: Pretreatment clinical photographs and panoramic

\section{Treatment Objectives}

The primary objectives of the treatment were to: (1) break thumb sucking habit, (2) correct anterior and low tongue rest position, and (3) correct anterior open bite and flared and spaced upper and lower incisors.

\section{Treatment Plan}

The plan consisted of two simultaneous approaches; the first was palatal crib to discourage sucking habit and to guide the tongue to rest in a normal position. The second approach was a daily myofunctional exercises practiced at home and supervized by the parents, to adapt normal tongue position at rest. These exercises included placing the tip of the tongue in the front area of the palate just behind the cribs, and then bring the tongue down forcefully to produce a popping sound. The second exercise was placing of the tip of the tongue in the front area of the palate as in the first exercise, but instead forces the tip of the tongue upward. The patient was instructed to perform each exercise at least 10 times at 3 different times a day.

\section{Treatment Progress}

The patient was cooperative and compliant and performed myofunctional exercises as planned. After 7 months, the open bite was completely corrected with retroclination of the flared maxillary and mandibular incisors and minimizing of the spaces. The facial and intraoral photographs (Fig. 2) showed retraction of maxillary and 
mandibular incisors, reduced spaces between incisors, an adequate overbite and overjet, increased incisal display on smiling, increased NLA, and decreased convexity of facial profile. Then, the palatal crib was removed and the patient was instructed to continue myofunctional exercises for at least 5 months to maintain the stability of the treatment results. To accelerate the eruption of the permanent canines, deciduous maxillary canines were extracted during this visit. Five months later, less frequency of myofunctional exercises were reported by the patient and his parents. The patient performed the exercise at least once daily during the whole period of 5 months. However, the results obtained from the first cycle of treatment were stable.
Two years post-treatment evaluation of the patient (Fig. 3) revealed good stability with more reduction in incisor spaces due to the eruption of permanents maxillary and mandibular canines. The patient referred for extraction of mandibular right primary second molar to stimulate eruption of its successor. Upon completion of eruption of permanents teeth, a second stage of treatment may be indicated with treatment objectives limited to alignment of incisors and closure of remaining spaces. Pretreatment and 2 years post-treatment lateral cephalometric radiographs and analysis results (Fig. 4) showed the significant improvement in facial profile, lip competency, incisors inclination and NLA angle.
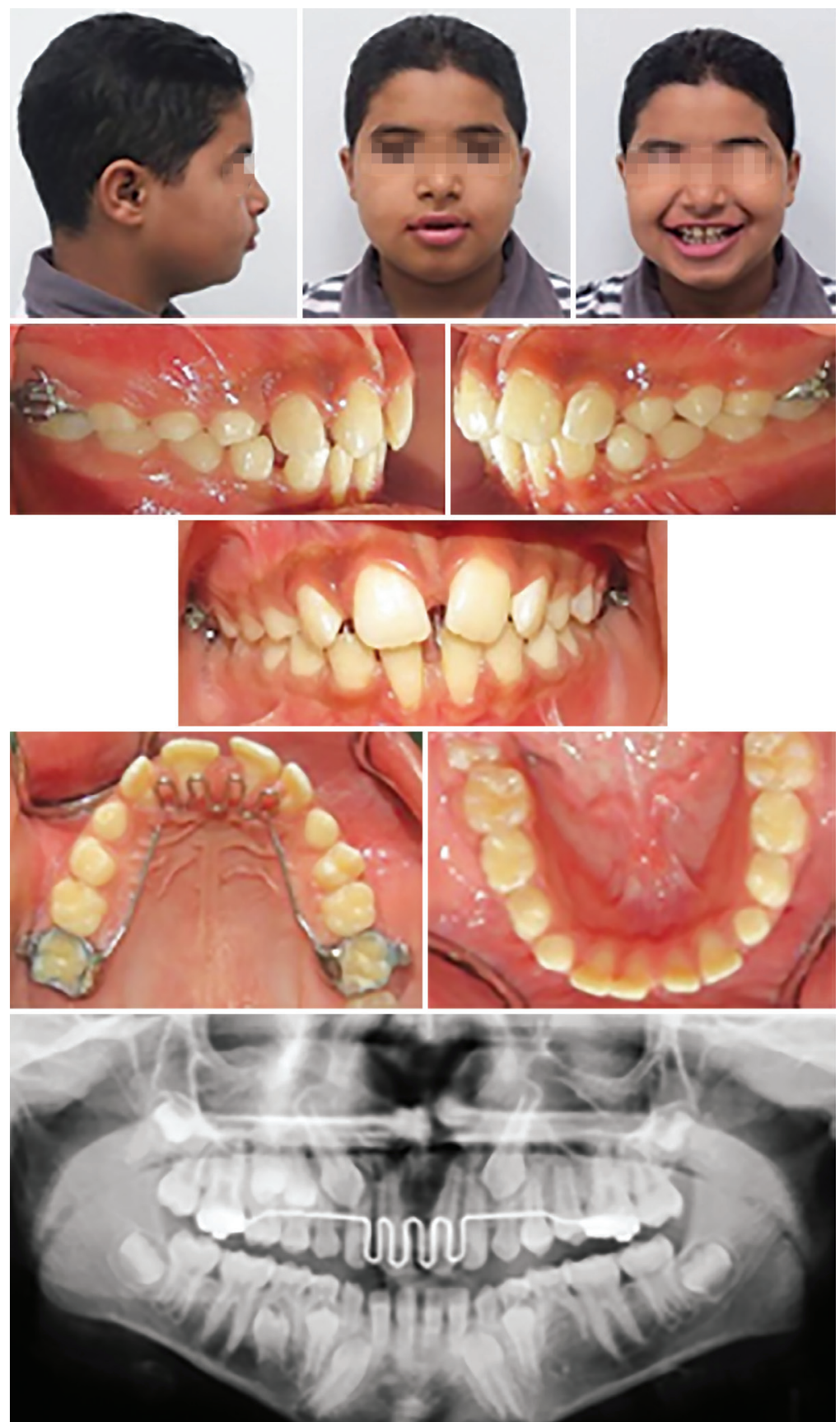

Fig. 2: Clinical photographs and panoramic radiograph after 7 months of treatment 


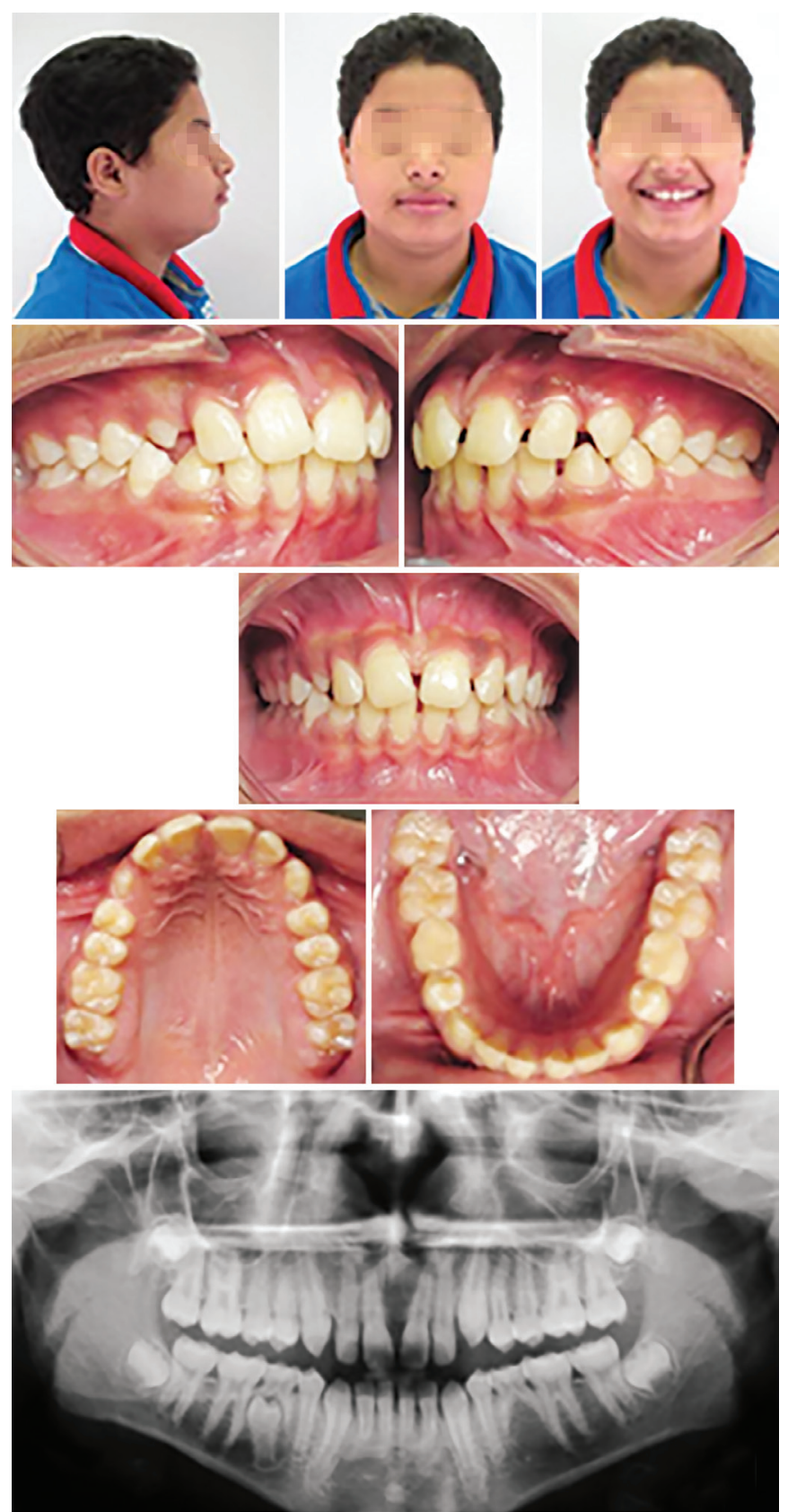

Fig. 3: Two years post-treatment clinical photographs and panoramic radiograph

\section{DISCUSSION}

This case report demonstrated the efficiency of palatal crib in discouraging thumb sucking habit with significant correction of $\mathrm{AOB}$ within 7 months, while myofunctional therapy was successful in adopting normal tongue position at rest and in maintaining the stability of the $\mathrm{AOB}$ correction. The total palatal crib treatment period was only 7 months. Then, the patient continued myofunctional exercises for another 5 months to reach the total of 12 months of myofunctional therapy. The treatment approach and duration demonstrated high efficacy in correcting the $\mathrm{AOB}$ and in maintaining the stability of the result.
Stability of the AOB correction is based on management of the factors that caused AOB. ${ }^{8}$ Smithpeter and Covell' ${ }^{9}$ stated that 'patients with anterior open bites accompanied by oral habits, speech errors, tongue thrust, and low forward tongue rest posture have a major risk for relapse after orthodontic treatment if these characteristics are not altered before removal of the orthodontic appliances. Further, Justus ${ }^{4}$ suggested that the primary reason for relapse of $\mathrm{AOB}$ might be failure of tongue posture adaptation. Furthermore, Smithpeter and Covell ${ }^{9}$ investigated the efficacy of myofunctional therapy for maintaining closure of open bites in conjunction with orthodontic treatment. They found that myofunctional therapy increased the stability of $\mathrm{AOB}$ correction in 
Anterior Open Bite treated with Myofunctional Therapy and Palatal Crib

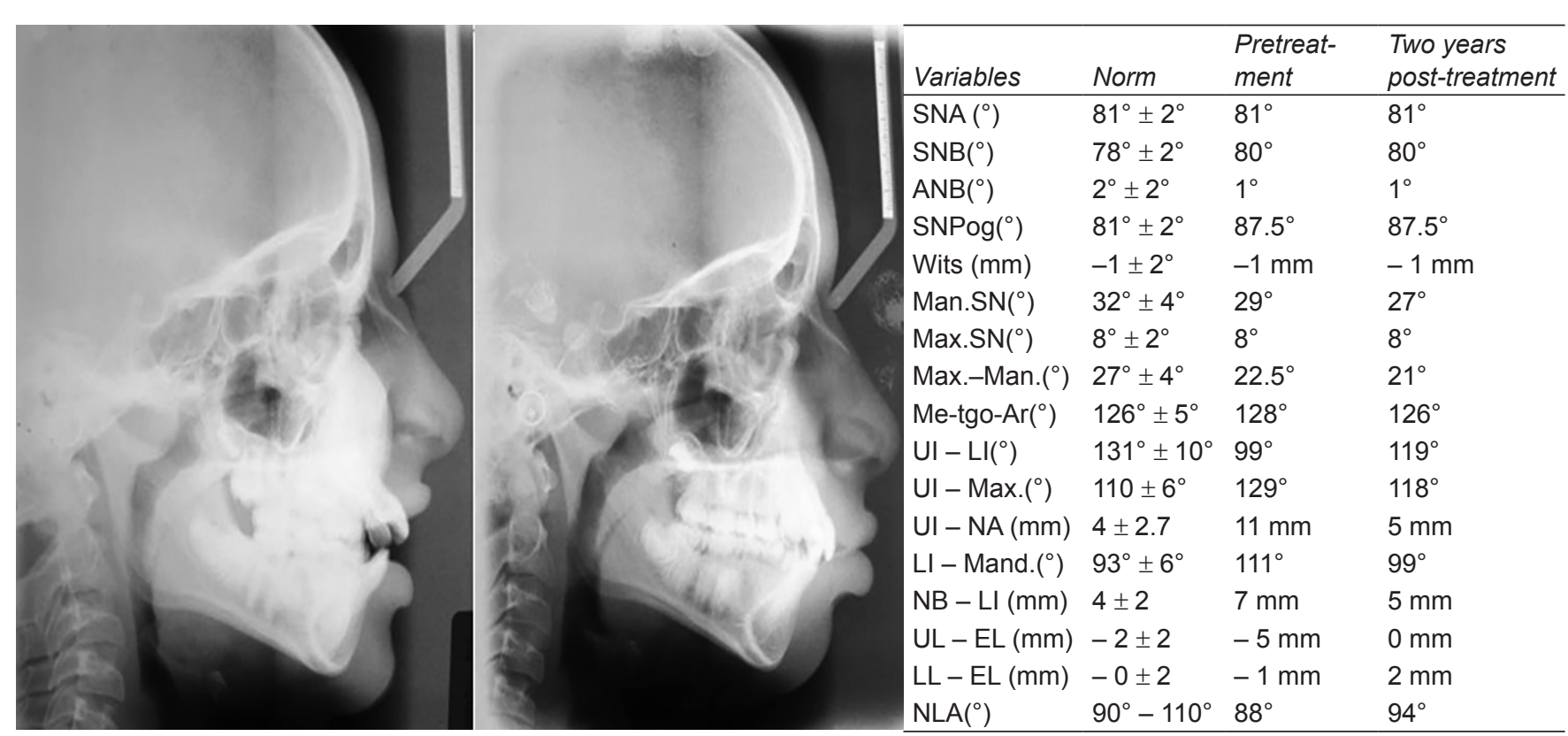

Fig. 4: Pretreatment and 2 years post-treatment lateral cephalometric radiographs and analysis results

patients who had forward tongue posture and tongue thrust. Palatal cribs correct AOB by discouraging thumb sucking habit and preventing the tongue from resting on the maxillary incisors. In some cases, palatal cribs may not be enough to control and adapt tongue position. Therefore, it should be combined with myofunctional therapy aimed to help the tongue in adapting its normal position. Degan and Puppin-Rontani ${ }^{3}$ concluded that myofunctional therapy associated to the discouraging of sucking habits presented a better and faster improvement of the tongue rest position. The myofunctional therapy eliminates physical forces and contributes for the re-arrangement of the oral cavity forces. ${ }^{3}$ On the contrary, other researchers ${ }^{10,11}$ believed that the myofunctional therapy works well with voluntary activities, such as swallowing while involuntary activities, such as tongue posture habits are hard to re-educate.

There is a need for more clinical studies to draw a clear picture for the role of myofunctional therapy and tongue posture in correcting the $\mathrm{AOB}$ and in maintaining the treatment result. Most of studies available in the literature are based on a case report or small sample with absence of control group.

\section{CONCLUSION}

Combination of palatal crib and myofunctional therapy was effective in treating anterior open bite due to thumb sucking habit and anterior and low tongue position. In addition, the myofunction therapy provided a better control for tongue position and enhanced the stability of open bite correction.

\section{REFERENCES}

1. Larsson E. Sucking chewing and feeding habits and the development of crossbite: a longitudinal study of girls from birth to 3 years of age. Angle Orthod 2001;71:116-119.

2. Degan VV, Puppin-Rontani RM. Prevalence of pacifiersucking habits and successful methods to eliminate them: a preliminary study. J Dent Child 2004;71:148-151.

3. Degan VV, Puppin-Rontani RM. Removal of sucking habits and myofunctional therapy: establishing swallowing and tongue rest position. Pró-Fono Revista de Atualização Científica. 2005;17:375-382.

4. Justus R. Correction of anterior open bite with spurs: longterm stability. World J Orthodont 2001;2:219-231.

5. Alderico Artese, Stephanie Drummond, Juliana Mendes do Nascimento and Flavia Artese. Criteria for diagnosing and treating anterior open bite with stability. Dental Press J Orthod 2011;16:136-161.

6. Cozza P, Baccetti T, Franchi L, McNamara JA Jr. Treatment effects of a modified quad-helix in patients with dentoskeletal open bites. Am J Orthodont Dentofac Orthoped 2006;129: 734-779.

7. Parker JH. The interception of the open bite in the early growth period. Angle Orthod 1971;41:24-44.

8. Alexander CD. Open bite, dental alveolar protrusion, class I malocclusion: a successful treatment result. Am J Orthod Dentofac Orthop 1999;116:494-500.

9. Smithpeter J, Covell D Jr. Relapse of anterior open bites treated with orthodontic appliances with and without orofacial myofunctional therapy. Am J Orthod Dentofac Orthop 2010;137:605-614.

10. Franco FC, Araújo TM, Pontas Ativas FH: um recurso para o tratamento da mordida aberta anterior. Ortodon Gaúch 2001;5:5-12.

11. Yashiro K, Takada K. Tongue muscle activity after orthodontic treatment of anterior open bite: a case report. Am J Orthod Dentofac Orthop 1999;115:660-666. 